\title{
Reassessing the economic value of advanced level mathematics
}

\author{
Michael Adkins*and Andrew Noyes \\ School of Education, University of Nottingham, Nottingham, UK
}

\begin{abstract}
In the late 1990s, the economic return to Advanced level (A-level) mathematics was examined. The analysis was based upon a series of log-linear models of earnings in the 1958 National Child Development Survey (NCDS) and the National Survey of 1980 Graduates and Diplomates. The core finding was that A-level mathematics had a unique earnings premium of $7-10 \%$ at age 33 . In recent years, this finding has contributed to the government's agenda of increasing participation in post-16 study of advanced mathematics in England. Given that the 1958 NCDS participants are now 57 years old, this paper repeats this important work using the 1970 British Cohort Study (BCS). Updated models are used to investigate whether the A-level mathematics premium also existed at age 34 for the 1970 BCS participants. There does appear to be a return of approximately $11 \%$ when replicating the original model closely but the robustness of this result depends on the model specification, sample size and the handling of missing data. We consider theoretical explanations of these findings and their implications for policy and future research.
\end{abstract}

Keywords - returns to education, A-level mathematics, economics of education, cohort analysis, multiple imputation

\section{Introduction}

Educational policy is currently framed by arguments about the importance of a range of flexible cognitive, quantitative and language skills for employment and the economy (e.g. see Truss 2013). The UK government has therefore been enacting a major reform agenda across upper secondary education in England. National qualifications for 16 year olds (GCSEs) and advanced qualifications for 18 year olds (A-levels) are being revised with mathematics qualifications and participation at upper secondary level receiving close attention. The government has committed to ensuring that all students continue studying mathematics post- 16 until they have reached a certain level of proficiency (GCSE grade C). Moreover, those who have already attained this level at the age of 16 are expected to continue with advanced mathematical study. In 2011, the then Secretary of State for Education, Michael Gove, stated his aspiration that by the end of the decade 'the vast majority' of young people should be studying mathematics to 18 (Gove 2015). New Core Maths qualifications are being launched in 2015 to help realise this ambitious goal.

Elizabeth Truss, the UK's Parliamentary Under-secretary of State for Education and Childcare from 2012 to 2014 was highly influential in focusing attention on post-16 advanced mathematics and we have discussed elsewhere her role in bringing Dolton and Vignoles' 1999; 2002 research to wider attention (A. Noyes \& M. Adkins, submitted). She argued that while mathematics A-levels were popular, the numbers studying mathematics post-16, and the levels achieved were behind many Organisation for Economic Co-operation and

\footnotetext{
*Corresponding author. Address: School of Education, University of Nottingham, Jubilee Campus, Wollaton Road, Nottingham, NG8 1BB, UK. Email: michael.adkins@nottingham.ac.uk
} 
Development (OECD) countries (Truss, 2013). While one of the arguments made for the drive to increase participation was a comparative one based on the work of Hodgen et al. (2010), the specific argument that has been most frequently used by the politicians is that people who take A-level mathematics earn on average 10\% more than their peers (see, e.g. Truss 2013; Morgan 2014; Gibb 2015). This specific research finding is one element of a growing body of work on the importance of mathematics/quantitative skills in the labour market (e.g. see Bynner and Parsons 1997; Greenwood et al. 2011; Crawford and Cribb 2013; Hanushek et al. 2015).

In the late 1990s, a review of 16-19 education in England (Dearing 1996) had called for research to better understand declining participation in mathematics and science subjects (see also Hawkes and Savage 1999). It was in response to this call that Dolton and Vignoles (1999) and Dolton and Vignoles (2002) undertook research to provide better labour market evidence on the economic return of A-levels. In brief, their research utilised the fifth wave of the National Child Development Study (University of London, Institute of Education, Centre for Longitudinal Studies 2008a; University of London, Institute of Education, Centre for Longitudinal Studies 2008b), as well as the 1980 Graduates and Diplomates Survey (Department of Employment, Employment Market Research Unit 2013), and suggested that A-level mathematics was unique in terms of its economic return. The extent of this return was $7-10 \%$ at age 33 .

There were several caveats discussed in the original research. Their participants were all male because of analytical decisions to drop female participants; they were born in 1958, took their A-levels in 1976, and were 33 at the time of the survey in 1991. Analysis of females was based upon the Graduate and Diplomates survey at a point six years after graduation but this is a different population subset. The researchers combined mathematics and computing as a single category, yet the computing element has generally been forgotten or ignored. (Note: we generally follow this trend but intermittently include computing to remind the reader of this elision.) Although Dolton and Vignoles discussed the uncertainty inherent in all statistics, this idea has disappeared in general usage of their research. Lastly, findings from the econometric models are only as good as the underpinning model assumptions, the quality of the data, statistical techniques and computational power.

It is clear from the research cited above that strong mathematical skills are critically important for a thriving and competitive knowledge-based economy. It is important, therefore, to have up-to-date research to inform decision makers on the returns on qualifications. Dolton and Vignoles' work needs to be updated for a number of reasons. There has been considerable change in the educational and economic landscape between 1974 (i.e. the year in which the 1958 cohort chose their A-levels) and 1991 (the age-33 data sweep) and today. A-level mathematics has undergone extensive reform over that time; the numbers taking A-levels has varied; the proportion of people completing their education at 18 has dropped; higher education has become more market-oriented; and, the economy is substantially different with the rapid expansion of the service sector and a substantial decline in traditional industries.

This paper repeats the analysis of Dolton and Vignoles (2002) with Wave 7 (2004) of the 1970 British Cohort Study (University of London, Institute of Education, Centre for Longitudinal Studies 2013b). It updates the original research with improvements relating to issues of (1) uncertainty, (2) omitted variable bias and (3) survey missingness. First, we follow the shift in research methodology to intervals and away from point estimation. Second, drawing on the work of Altonji et al. (2012) we investigate omitted variable bias. Third, the original work dealt with substantial amounts of missing data via ad hoc measures, although this has the potential to introduce bias into the regression estimates. Instead, we make use of multiple imputation approaches.

Our major findings demonstrate the sustained economic value of mathematics skills between the NCDS and BCS cohorts. The strength and direction of the relationship between earnings and measures of mathematics skills at age 10 and 16, as well as in completion of A-level is striking. Our repeat of Dolton and Vignoles (2002) work suggests a sustained premium for A-level mathematics (and computing) of around $11 \%$ at age 34 in the 1970 BCS sample. However, we also highlight the range and uncertainty inherent in 
these returns and show that, for this sample, some caution is needed to avoid overly simplistic interpretation of the findings.

At this point it is worth outlining the structure of the upper secondary qualifications system in England as it was in 1988, the year in which the BCS participants took A-levels. Up to 1988 young people completed their compulsory schooling at age 16 (Year 11) either with Ordinary level (O-level) qualifications, or CSEs (Certificates of Secondary Education). From 1988 onwards these were combined as the General Certificate of Secondary Education (GCSE), which has continued to this day. Students with O-levels often continued on an academic pathway with Advanced or A-level qualifications. Although these have changed considerably over the years, A-levels continue to be the standard university-entrance qualifications and most students would study three or four subjects over the following two years, up to the age of 18 .

This paper will be structured as follows. We discuss two theoretical explanations of qualification returns: signalling and human capital. Next, we detail our data and methodology addressing data cleaning, modelling and missing case analysis. The subsequent section is split into three parts. The first part presents the results from five models that work up to a repeat of Dolton and Vignoles's 2002 analysis. The second presents the research findings from a substantially extended model that aims to address issues of omitted variable bias as far as the data allows. The third section discusses predicted earnings and the uncertainty inherent in the model. Lastly, we discuss the impact of our research findings on the current state of policy reforms.

\section{Theory}

Employers are in a difficult position when taking on new staff. They exist in a world of imperfect information regarding the potential skill level and productivity of candidate employees, which raises the cost of hiring new staff for organisations. In most job markets the employer cannot be sure of the productive capabilities of the individual at the time of hiring. These capabilities will also not necessarily become clear immediately after hiring owing to time taken to learn the job or undertake training (Spence 1973, p. 356). Mincer (1974) argued that earnings were a function of years of schooling and years of experience in the labour market, with the impact of schooling diminishing over time. As employers come to understand employees' productivity, the risks are reduced and wage rewards accrue. Up until that time, qualifications play an important role.

There are two theories of the role of education with regards to this wage equation: human capital and ability signalling (Spence 1973). The theory of human capital is rooted in the work of Hardt et al. (2012b) and Schultz (1961) and is concerned with how learning explains the economic return to schooling (Weiss 1995). In essence, students learn specific skills and acquire knowledge and these have currency in the workplace. Individuals must trade-off immediate income benefit with delayed, but increased, wage returns that arise from gaining additional education and/or training (Becker, 1975).

The theory of signalling argues that employers observe personal data as unalterable indices (e.g. age, sex and ethnicity) with changeable attributes such as education and experience in the job market. The employer, based on their experience, estimates the probability of the suitability of the employee and their likely productivity based on this range of indices and attributes (Spence 1973). However, much of the work on labour market signalling is based on research conducted in the USA where the standard certificate of secondary education is the High School Diploma, which does not differentiate on the basis of performance in individual subjects. According to Weiss (1995), students will choose a length of schooling to signal their ability to employers and employers will demand a minimum level of schooling from applicants to screen workers. This mechanism essentially sorts candidates on the observed and unobserved but correlated employability traits (Weiss 1995, p. 134).

The qualifications landscape in England potentially leads to earlier direct signalling. The structure of A-level qualifications provides employers with clear and direct signals of specialised abilities as well as general attitudes and attributes. Degrees are likely to provide a similar range of direct signals. So, rather than 
education communicating a generic ability level, employers gain much more detailed information on specific abilities, attitudes and attributes, allowing for greater nuance in wage returns for a given education level and specialisation. What combination of abilities, attitudes and other attributes is being signalled remains unclear. So, while a choice to study arts or science A-level, for example, might indicate particular abilities it also signals a range of other things.

\section{Data and methods}

\section{Data $^{1}$}

The 1970 BCS includes five major waves of data collection after the age of 16 . These took place in 1996 (Bynner and London 2013), 2000 (University of London, Institute of Education, Centre for Longitudinal Studies 2013c), 2004 (University of London, Institute of Education, Centre for Longitudinal Studies 2013b), 2008 (University of London, Institute of Education, Centre for Longitudinal Studies 2013a) and 2012 (University of London, Institute of Education, Centre for Longitudinal Studies 2014). Wave 7 (2004) is our primary dataset and includes information on demographics, pay and work experience, sex, marital status, number of children, respondents' occupational social class, region of residence, salary, hours worked and length of current job. Importantly, Wave 7 gathered detailed data on work histories from 1996 to 2004 that supplied information for total work experience and unemployment.

The earlier waves provide extensive data for our merged dataset. Wave 6 was conducted in 1999/2000 when the participants were approximately 29-30 years of age and provided key post-16 educational achievement variables such as A-level subjects completed (grade data was unavailable), NVQs, professional qualifications and degree subjects. Key ability test scores, parental aspirations, employment and education experience, along with cohort members' occupational and educational aspirations were collected at Wave 3 (Butler et al. 2014) and 4 (Butler et al. 2013) in 1980 and 1986 respectively. Importantly, Wave 4 also includes GCE O-level grades for English and Mathematics. In addition to this, we utilised demographics, pay and work experience data from Wave 5 (1996), Wave 6 (2000), Wave 8 (2008) and Wave 9 (2012) for auxiliary variables. Auxiliary variables are used within missing case analysis to supply additional information and this is discussed below.

\section{Sample}

Our initial requirement for inclusion in the final dataset was that the respondent had been part of at least one post-16 wave of the BCS. Longitudinal datasets provide unique opportunities to incorporate respondents who may have missed one wave, but have then returned in later waves. Multiple imputation deals with missing values in partially observed cases contingent on all of the observed data. A total initial sample size of approximately 13,620 was achieved. For the final fitment of the model we used a subset of this sample based on two characteristics: (1) having completed at least one A-level and (2) being employed in either full-time ( $>30$ hours per week) or part-time work. This reduced the sample size to approximately 2027 respondents (i.e. $15 \%$ of the total).

\section{Modelling}

Six single-level log-linear models of increasing complexity were developed with model fit compared via the R2 statistic. A null model was used to estimate the overall average pay and then we added a set of demographic variables (sex of respondent, marital status, whether the respondent has any children, their occupational class and region of residence) for Model 2. Model 3 added basic qualifications up to the age of

\footnotetext{
${ }^{1}$ Materials for replicating the analysis are available at: http://dx . doi .org/10.7910/DVN/EAXI4K
} 
18 controlling for subjects completed rather than level of attainment. Model 4 added the remaining post-18 qualifications available: NVQ, higher education diploma, degree and professional qualification. Model 5 took the form of a replication of Dolton and Vignoles' 2002 model, as far as it was possible, adding work experience variables and age 10 ability scores. Finally, model 6 addresses the issue of omitted variable bias as far as the available data allows and, importantly, exchanges the participants' occupational social class for their parental social class at age 16 and other measures. The final two models are presented below:

Equation (1) represents Model 5, the log of annual salary against a range of demographic, educational, work experience and ability predictors.

$$
\begin{aligned}
& (\log ) y_{i}=\alpha+\beta_{1}^{\text {Female }_{i}}+\beta_{2}^{\text {Married }_{i}}+\beta_{3}^{\text {Children }_{i}}+\beta_{4}^{\text {Part_time }_{i}}+\beta_{5}^{\text {SC:IIManagerial_technical }_{i}} \\
& +\beta_{6}^{S C: 3: 1 S K \text { Non-Manual }_{i}}+\beta_{7}^{S C: 3: 2 S K-\text { Manual }_{i}}+\beta_{8}^{S C: \text { IVPartlySkilled }_{i}} \\
& +\beta_{9}^{S C: V_{-} \text {Unskilled }_{i}}+\beta_{10}^{S C: \text { Others }_{i}}+\beta_{11}^{\text {Residence_East_Midlands }}{ }_{i}+\beta_{12}^{\text {Residence_East_England }_{i}} \\
& +\beta_{13}^{\text {Residence_North_East }}+\beta_{14}^{\text {Residence_North_West }}+\beta_{15}^{\text {Residence_South_East }} \text { F }_{i} \\
& +\beta_{16}^{\text {Residence_South_West }}+\beta_{17}^{\text {Residence_West_Midlands }}+\beta_{18}^{\text {Residence_Yorkshire }}{ }_{i} \\
& +\beta_{19}^{\text {Residence_Scotland }_{i}}+\beta_{20}^{\text {Residence_Wales }_{i}}+\beta_{21}^{\text {Degree }_{i}}+\beta_{22}^{N V Q_{i}}+\beta_{23}^{\text {Prof_Qual }_{i}} \\
& +\beta_{24}^{\text {HE_Diploma }_{i}}+\beta_{25}^{\text {Maths_Computing }_{i}}+\beta_{26}^{\text {Science }_{i}}+\beta_{27}^{\text {Humanities }_{i}} \\
& +\beta_{28}^{\text {Social_Science }_{i}}+\beta_{29}^{\text {Other }_{i}}+\beta_{30}^{\text {Work_Experience }_{i}}+\beta_{31}^{\text {Work_Experience }_{i}^{2}}+\beta_{32}^{\text {Tenure }_{i}} \\
& +\beta_{33}^{\text {Unemployment }}+\beta_{34}^{\text {Age_10_Maths_Scorei }}+\beta_{35}^{\text {Age_10_Reading_Score }}+\epsilon_{i}
\end{aligned}
$$

$$
\epsilon_{i} \sim \mathcal{N}\left(0, \sigma^{2}\right)
$$


Equation (2) represents Model 6, the log of annual salary against a range of demographic, educational, work experience, ability predictors and additional predictors to address omitted variable bias issues further

$$
\begin{aligned}
& (\log ) y_{i}=\alpha+\beta_{1}^{\text {Female }_{i}}+\beta_{2}^{\text {Married }_{i}}+\beta_{3}^{\text {Children }_{i}}+\beta_{4}^{\text {Part_time }_{i}}+\beta_{5}^{\text {PSC:IIManagerial_technicali }} \\
& +\beta_{6}^{\text {PSC:3:1SK_Non-Manuali }}+\beta_{7}^{\text {PSC:3:2_SK_Manual }}+\beta_{8}^{\text {PSC:IV_Partly_Skilled }} \\
& +\beta_{9}^{\text {PSC:V_SK_Unskilledi }}+\beta_{10}^{\text {Residence_East_Midlands }}{ }_{i}+\beta_{11}^{\text {Residence_East_England }_{i}} \\
& +\beta_{12}^{\text {Residence_North_East }}+\beta_{13}^{\text {Residence_North_West }}+\beta_{14}^{\text {Residence_South_East }} \\
& +\beta_{15}^{\text {Residence_South_West }}+\beta_{16}^{\text {Residence_West_Midlands } s_{i}}+\beta_{17}^{\text {Residence_Yorkshire }_{i}} \\
& +\beta_{18}^{\text {Residence_Scotland }_{i}}+\beta_{19}^{\text {Residence_Wales }_{i}}+\beta_{20}^{\text {Degree }_{i}}+\beta_{21}^{N V Q_{i}}+\beta_{22}^{\text {Prof_Qual }_{i}} \\
& +\beta_{23}^{\text {HE}_{-} \text {Diploma }_{i}}+\beta_{24}^{\text {Maths_Computing }_{i}}+\beta_{25}^{\text {Science }_{i}}+\beta_{26}^{\text {Humanities }_{i}}+\beta_{27}^{\text {Social_Science }_{i}} \\
& +\beta_{28}^{\text {Other }_{i}}+\beta_{29}^{\text {Work_Experience }_{i}}+\beta_{30}^{\text {Work_Experience }_{i}^{2}}+\beta_{31}^{\text {Tenure }_{i}}+\beta_{32}^{\text {Unemployment }_{i}} \\
& +\beta_{33}^{\text {Age_10_Maths_Scorei }}+\beta_{34}^{\text {Age_10_Reading_Score } i}+\beta_{35}^{\text {Maths_Olevel }_{i}}+\beta_{36}^{\text {English_Olevel }_{i}} \\
& +\beta_{37}^{\text {Age_Mother_finished_ed }}+\beta_{38}^{\text {Age_Father_finished_ed }}+\beta_{39}^{\text {MotheremployedCM16 } i} \\
& +\beta_{40}^{\text {Private_school }_{i}}+\beta_{41}^{\text {Single_sex_school }_{i}}+\beta_{42}^{\text {Post-18_educ_asp }}+\beta_{43}^{\text {Prof_occ_asp }_{i}}+\epsilon_{i} \\
& \epsilon_{i} \sim \mathcal{N}\left(0, \sigma^{2}\right)
\end{aligned}
$$

\section{Data cleaning}

The BCS data required extensive cleaning and eight datasets were merged to create our final data frame. Table 1 highlights the source and type of each original variable and the transformation used to create each of the input variables used in the models. Table 2 shows the way in which the A-level subject categories were constructed.

\section{Omitted variable bias}

The impact of omitting variables that might predict educational and career choices is an issue with these types of investigations and requires careful consideration. Those undertaking A-levels are a selective higher ability group (15\% of the BCS cohort), approximately $62 \%$ of whom proceeded to university. While academic ability measures will be highly correlated with the decision to study A-levels and degrees, there are further variables that might predict this choice, for example parental education levels. Altonji et al. (2012) investigated these issues noting that educational and occupational pathways are heterogeneous in nature and are shaped by parental and peer preferences, innate abilities, pre-existing skills and knowledge, as well as additional preferences, abilities, skills and knowledge that vary over time. Dolton and Vignoles' 2002 model controlled for prior ability at age 16, and they also explored the usefulness of age 7 and 10 test scores and O-level mathematics. Family social class variables were not available to them, but they did include a measure of the socio-economic profile of the participant's class and school.

As in the original paper, we had the advantage of working with a rich longitudinal study that had substantial records of parent and cohort member preferences, various measures of ability and the potential to map these and other attributes over time. Drawing on Schoon et al. (1976), we developed an additional model (Model 6) to explore issues of omitted variable bias, but reduced the parsimony of the model as a 


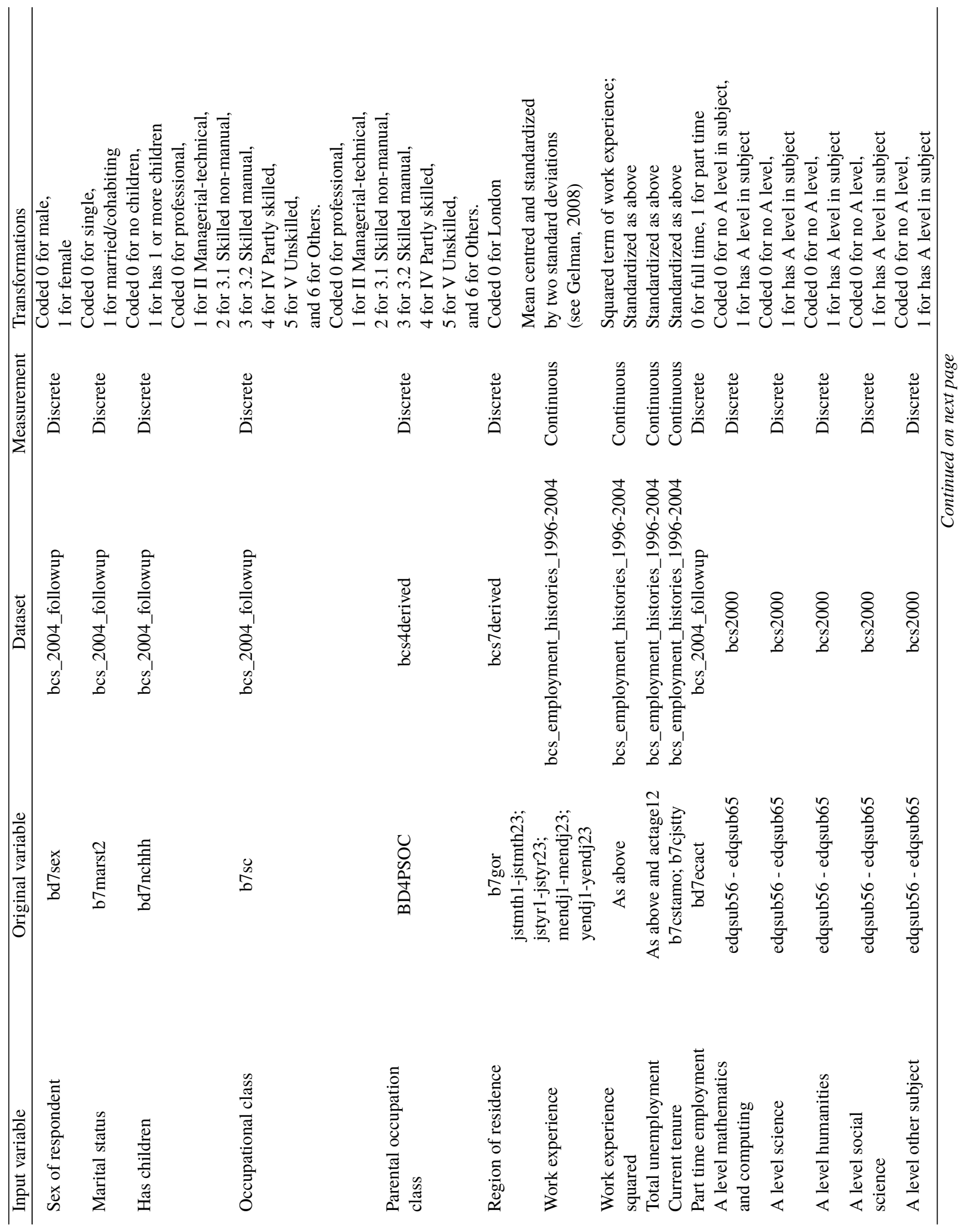




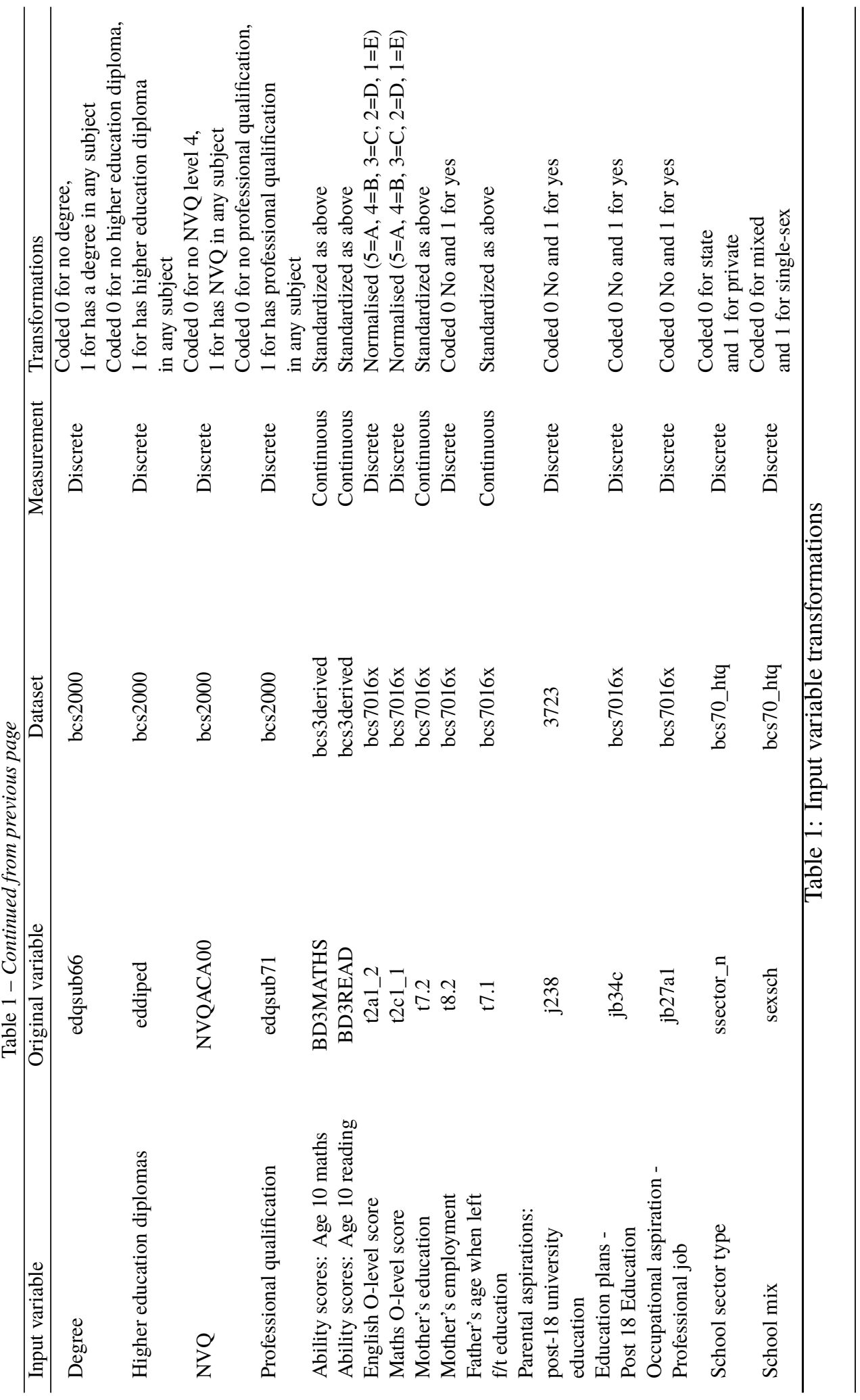


result. We found that most of these additional measures (such as English and Mathematics O-level grade, age of respondents' parents when they left full-time education, parents' aspirations for their children to study at university, respondents' occupational and educational aspirations, school sector type and school mix) had little impact on the overall model, but the A-level premium hovered around the acceptable boundaries of statistical significance. We discuss this further below. However, it should be noted that while we can test whether including additional variables influences the main findings, we cannot necessarily fully eliminate the possibility of further omitted variables biasing the results.

\begin{tabular}{lllll}
\hline Maths and Computing A level & Science A level & Humanities A level & Social Science A level & Other A level \\
\hline Maths & Biology & Ancient Greek & Business Studies & Art \\
Maths S level & Biology other & Ancient History & Geography & Art and Design \\
Further Maths & Biology S level & Archaeology & Economics & Art History \\
Computer Science & Chemistry & English & Government and Politics & Film Studies \\
& Geology & French & General Studies & Graphic design \\
& Physics & German & Law & Music \\
& Science Other & Spanish & Social Policy & \\
& Zoology & Italian & Social Studies & \\
& & Greek & Sociology & \\
& & History & Sports Studies & \\
\hline
\end{tabular}

Table 2: A level subject categories

\section{Missing data and imputation}

Missingness in the BCS is a critical issue to address for several reasons. First, the BCS has seen a fair amount of inter-wave attrition. The initial wave recruited approximately 18,000 and across the adult waves from age 26 to 42 approximately 13,620 have taken part in at least one survey. Second, the data missingness pattern is somewhat arbitrary with some respondents returning to the study after missing out a few waves and others leaving completely. Third, there is non-response to specific items within a wave, in particular, the parameters of interest. Most of the analytic variables displayed varying degrees of missingness (see Table 3) and while all of these variables can be effectively imputed, the higher the proportion of missingness, the greater likelihood that the results are influenced by the choice of imputation model.There are no agreed cut-offs for acceptable percentages of missingness (Dong and Peng 2013) and Tabachnick and Fidell (2012) argue that the pattern of any missingness is more critical than its extent.

We employed a technique called Multiple Imputation Chained Equations (MICE) that sequentially imputes each variable and can handle variables that are based on different distributions, for example continuous, binary, ordered and unordered categorical, and count data (Van Buuren et al. 1999b, see Royston and White 2011) for a detailed discussion of the MICE imputation process.

The imputation model needed to deal with three issues: (1) auxiliary variables, (2) imputation of the outcome variable, and (3) linear transformations. Theoretically, imputation assumes that missing data are dependent on the observed data (referred to as 'missing at random', see Rubin 1976a; Little and Rubin 1987; Little and Rubin 2002). The plausibility of this assumption is enhanced by increasing the pool of observed variables as this reduces the degree to which missingness is dependent on unobservables (Gelman et al. 2014, p. 450). Therefore, we included all of the variables from the analytical model and added auxiliary variables such as salary, respondents' and parental occupational social class, marital status and part-time work from the previous and subsequent waves. One advantage of this approach was that it dealt with the second 


\begin{tabular}{lr}
\hline Analytical Model Variable & Probability of being observed \\
\hline Salary at age 34 & 0.4662261 \\
Female & 0.9987518 \\
Married & 0.7077827 \\
Children & 0.7070485 \\
Residence & 0.7093245 \\
Degree & 0.8267988 \\
NVQ & 0.8267988 \\
Professional Qualification & 1 \\
Higher Education Diploma & 0.9999266 \\
Mathematics and Computing A level & 0.8267988 \\
Science A level & 0.8267988 \\
Humanities A level & 0.8267988 \\
Social Science A level & 0.8267988 \\
Other A level & 0.8267988 \\
Work Experience & 0.9459618 \\
Work Experience Squared & 0.9459618 \\
Current Tenure & 0.1803231 \\
Unemployment & 0.9459618 \\
Age 10 Maths Score & 0.7299559 \\
Age 10 Reading Score & 0.7299559 \\
Part time & 0.588326 \\
Parent Social Class & 0.8256241 \\
School mix & 0.2870778 \\
School type & 0.29163 \\
Professional Occupation Aspiration & 0.4357562 \\
Post 18 Education & 0.1953744 \\
English O level Score & 0.2659325 \\
Maths O level Score & 0.213583 \\
Mother Employed when CM 16 & 0.463583 \\
Working at age 34 & 0.707489 \\
Has at least one A level & 0.8267988 \\
Age Father finished education & 0.4601322 \\
Age Mother finished education & 0.473862 \\
\hline
\end{tabular}

Table 3: Analytical variable probability of being fully observed

issue (imputation of the outcome variable), avoiding the need to use multiple imputation then deletion (see Von Hippel 2007, p. 87 because the auxiliary variables provide critical information to deal with the random component of the imputed values. Lastly, we made use of two transformations - a logarithm and square term - which we chose to transform then impute to avoid rounding and the bias that this might introduce (see Von Hippel 2009, pp. 271-272). While the plausibility of the missing at random assumption can be increased, the possibility that data might be missing not at random cannot be fully eliminated. Although there may still be bias, multiple imputation can offer a marked improvement over classical complete case analyses.

We generated 40 imputations with burn-in set at 20 iterations that produced 800 iterations in total thereby 
ensuring low autocorrelation between the imputed datasets (for a discussion of required numbers, see Rubin 1976b, p. 480, Graham et al. 2008, p. 212, Hardt et al. 2012a, p. 187, White et al. 2011, pp. 387-388). The imputations were conducted in R using MICE (Van Buuren et al. 1999a) on a high performance computing cluster. Once complete, the Markov Chain Monte Carlo (MCMC) traces were visually inspected for evidence of good mixing and sensitivity analyses were performed (see Abayomi et al. 2008), which indicated that the algorithm had converged and had drawn plausible values.

\section{Results}

\section{Model fit}

As discussed earlier, we fitted six models of increasing complexity, the results of which are set out in Table 4. The discussion focuses on Models 5 and 6. Table 5 highlights the change in the fit between each model. Despite the inherent weaknesses in the $\mathrm{R}^{2}$ statistic, it is notable that model fit does not improve much between Models 2 and 5. Model 6 addresses omitted variable bias, in part by replacing the occupational social class variable of Models 2-5, adding family and other social background variables and as a result of this additional complexity the model fit reduces slightly. There is a general downward trend in the baseline income as the control group becomes more complex. For Model 5 the control is male, single with no children, working a full-time job of over 30 hours per week, residing in London, working in a professional occupation, with 1 A-level only; he is one standard deviation below the mean on the following variables: work experience, tenure in the current post, level of unemployment after finishing education and age 10 mathematics and reading scores. For Model 6, the control was the same as Model 5, with the addition that he is one standard deviation below average mathematics and English O-level scores, his parents finished school below the average age, his mother was not employed when he was 16, he attended a mixed-sex state school and did not aspire to either post-18 education or a professional occupation.

\section{Effect sizes}

The coefficient plots below illustrate, for Models 5 and 6 (Figures 1 and 2, respectively), the point estimates of each regression input along with a measure of uncertainty. Any input that crosses zero is deemed to be not statistically significant. Each coefficient represents the unique effect of this particular factor, i.e. the amount of money earned in addition to the baseline annual income (at 2015 prices) when there is a one unit change in that particular input. For the discrete variables this is easily interpreted as the difference in earnings by being a member of a particular group, for example being female. For the standardised continuous variables that have been mean-centred and then divided by two standard deviations, a one unit change represents a move from one standard deviation below the mean level of a particular variable to one standard deviation above the mean. 


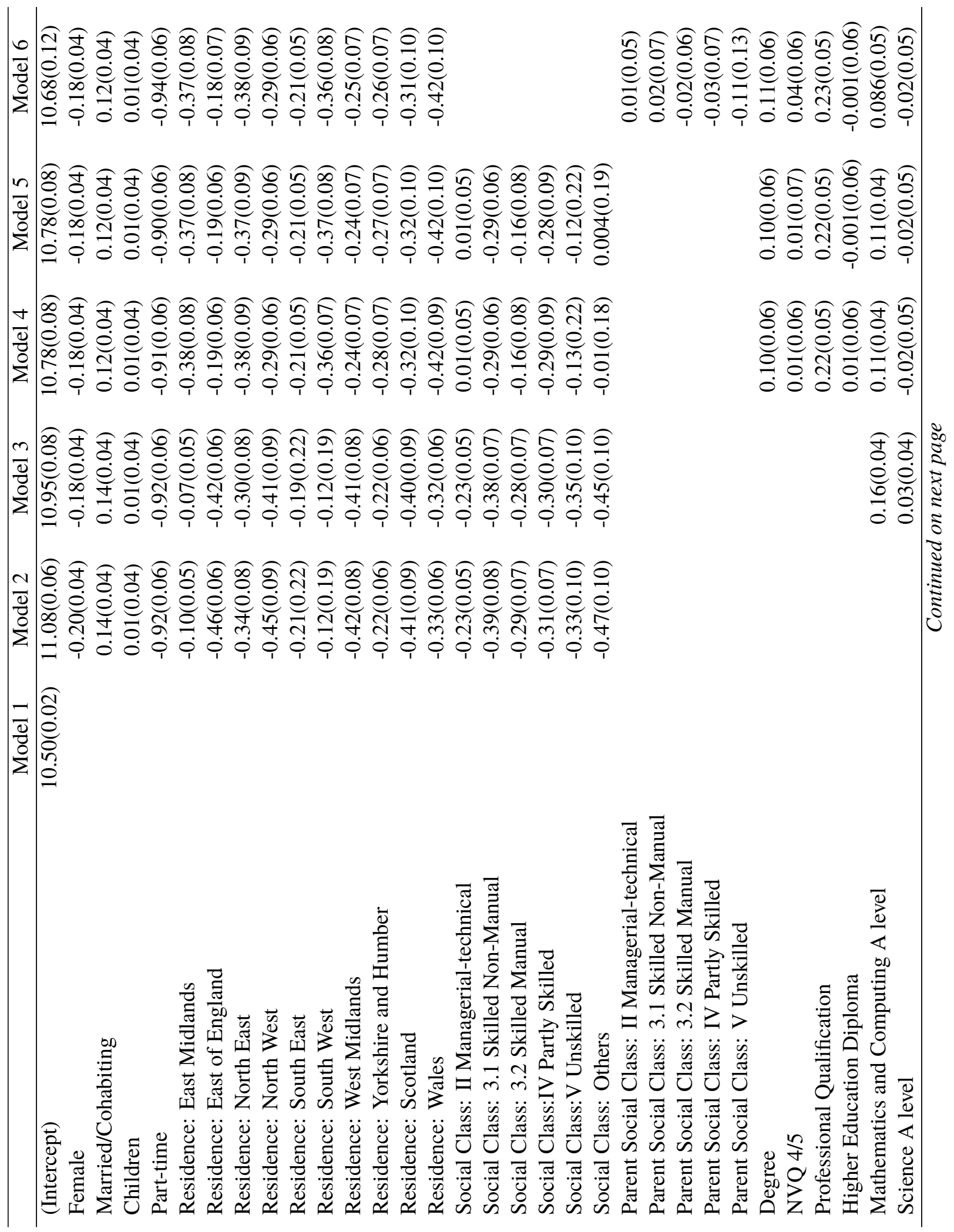




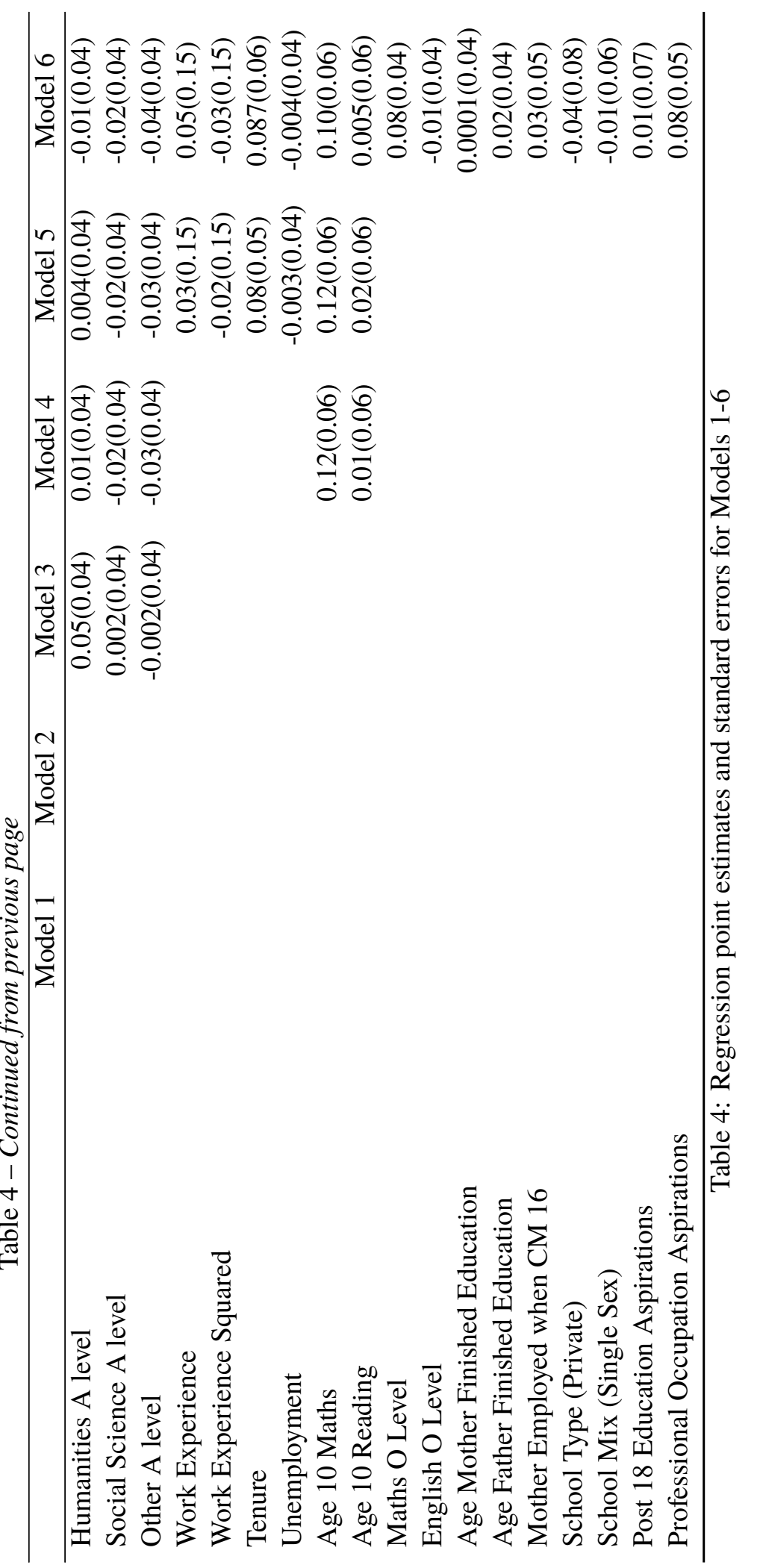




\begin{tabular}{lccc}
\hline Model & Adjusted $\mathrm{R}^{2}$ & Mean Baseline Income in $£$ & Baseline Income Intervals in $£$ \\
\hline 1 & N/A & 36230 & {$[34720: 37950]$} \\
2 & {$[0.3025242: 0.3844625]$} & 64690 & {$[57500: 72780]$} \\
3 & {$[0.3110464: 0.3932138]$} & 57150 & {$[49010: 66650]$} \\
4 & {$[0.3319272: 0.4145248]$} & 47930 & {$[40820: 56290]$} \\
5 & {$[0.3342336: 0.4171729]$} & 48280 & {$[41140: 56670]$} \\
6 & {$[0.3173154: 0.4017867]$} & 43670 & {$[34690: 54960]$} \\
\hline
\end{tabular}

Table 5: Model fit and baseline income-rounded to the nearest $£ 10$

\section{Model 5}

Comparing individual characteristics and demographics with the point estimate of our intercept (the average baseline income) highlights a number of general effects, some of which are well documented in the literature. Those respondents who are female earn on average $£ 40,160$ with a narrow confidence interval of between $£ 37,280$ and $£ 43,250$. Therefore the average female cohort member earns just $80 \%$ of the baseline income - approximately $£ 8000$ less than the average male. Region of residence is particularly important, with the average respondent earning substantially less in all areas of England outside London. The East Midlands saw average earnings of $£ 33,220$ ( $£ 29,950-£ 40,440$ ), North East was $£ 33,190$ ( $£ 27,720-£ 39,740$ ), South West was $£ 28,790$ ( $£ 28,790-£ 38,800$ ), Scotland was $£ 28,820$ ( $£ 28,790-£ 38,800$ ) and Wales was $£ 26,390$ (£26,390-£38,210).

Considering participants' occupational social class, the signal is difficult to distinguish from the noise in the model. Unsurprisingly, there was a more substantial difference in average earnings for participants in skilled non-manual, skilled manual and partly skilled sub-groups. Skilled non-manual workers earned on average $25.4 \%$ less, skilled manual workers earned $20.7 \%$ less and partly skilled workers $24.5 \%$ less than the average salary of professional workers.

All respondents included in the model have A-levels, but having an A-level in science, humanities, social science or other category is not associated with increased income. However, those with mathematics and/or computing, as in Dolton and Vignoles' NCDS analysis, earned on average approximately 11\% more than their A-level peers. It is important to note that the variability around this estimate is substantial with the confidence intervals stretching from $2 \%$ to $21.4 \%$. In monetary terms this equates to earnings of $£ 53,720$ with an interval of $£ 49,220-£ 58,640$. Beyond A-level, only the professional qualification measure was statistically significant with an average effect size of $21.2 \%$. It is a catch all variable and not one from which we can draw too many conclusions.

Finally, examining the work experience and ability controls we find that most inputs have produced small effect sizes and are not statistically significant. The exception was the mathematics age 10 ability score that showed that a one unit movement produced an average increase in earnings of $11.7 \%$, which is approximately $£ 54,350$ with an interval of $£ 48,740$ - 60,600 . This ability measure is different in nature from qualification results (e.g. O-level and A-level) in that the latter could act as a direct signal. Irrespective of whether these participants have completed an A-level in mathematics, the age 10 maths score predicts earnings over 20 years later, for this cohort. While this suggests a human capital argument for the value of maths skills, it is less clear cut whether ability signalling or human capital offers the best explanation for the A-level mathematics premium.

Dolton and Vignoles found that A-level mathematics did not predict first job earnings and so were inclined towards a human capital argument because signalling effects would appear immediately. Although the primary goal of our research was to repeat their age-33 model, we did run preliminary models with 


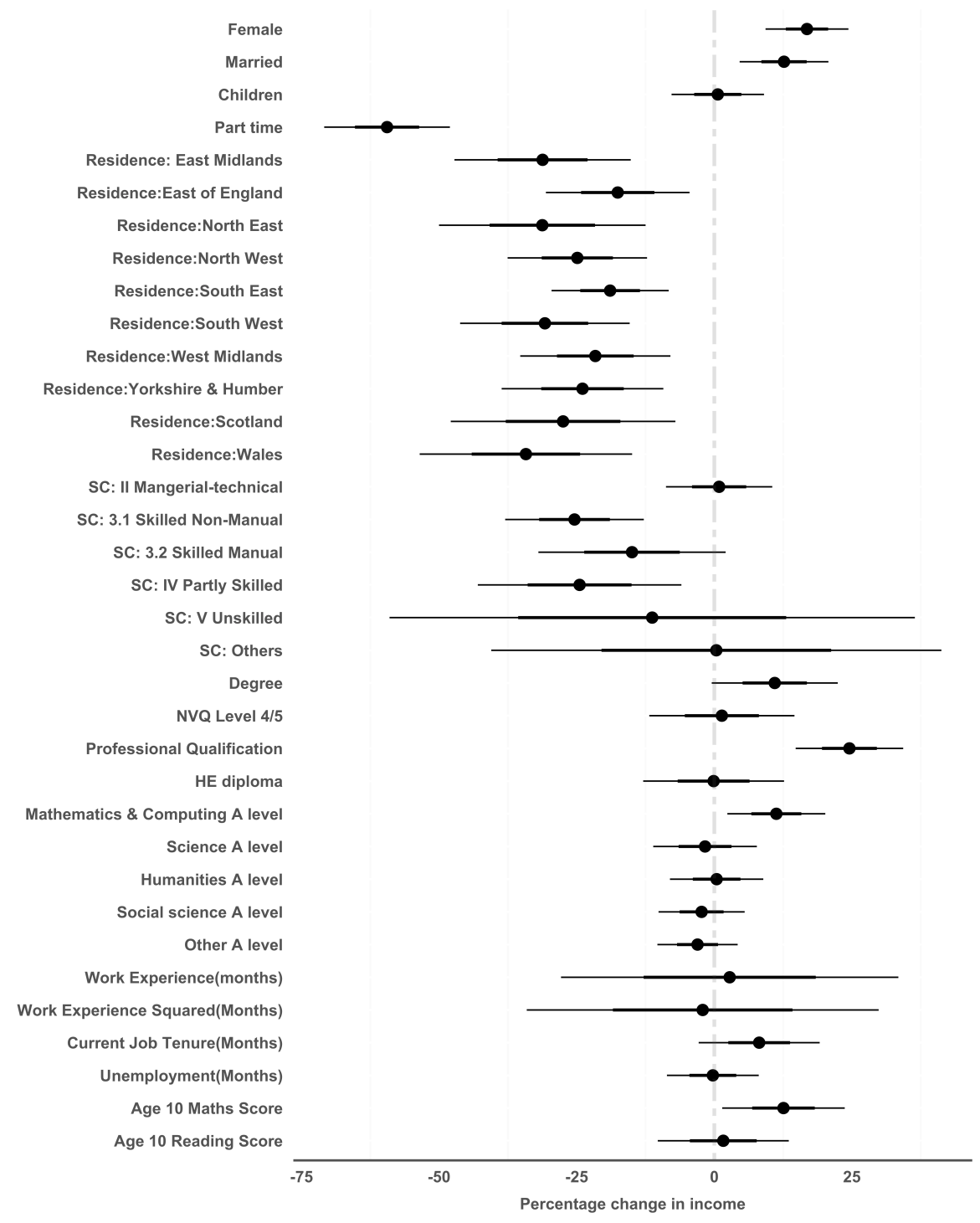

Figure 1: Coefficient plot of estimates for Model 5. Baseline income is approximately $£ 48,280$ [£41,140:£56,670], and is based on an individual who is male, single, has no children, works in a professional occupation, resides in London, has one A level and has 1 standard deviation below average work experience, unemployment, current job tenure and ability scores at age 10 in mathematics and reading

a smaller, non-imputed sample of the age- 26 wave of the BCS and found a significant return to A-level mathematics of around 7\%. This suggests a possible qualification signalling effect because of the early reward but exactly what is being signalled remains unclear. This is a subtle argument about what it means to have A-level mathematics. It is no doubt the case that learners have acquired more mathematics (though little of it might be applicable in the contexts in which they earned a wage premium) but they have also had to think quantitatively, struggle with abstract problems, identify as someone who wants to study maths, and so on. It might well be that these attitudes and attributes are part of the signal. Some caution needs to be exercised regarding the signal of the A-level mathematics qualification. While we have observed a return relatively early in the respondents' careers, we have no data on post-graduation starting salaries and therefore 


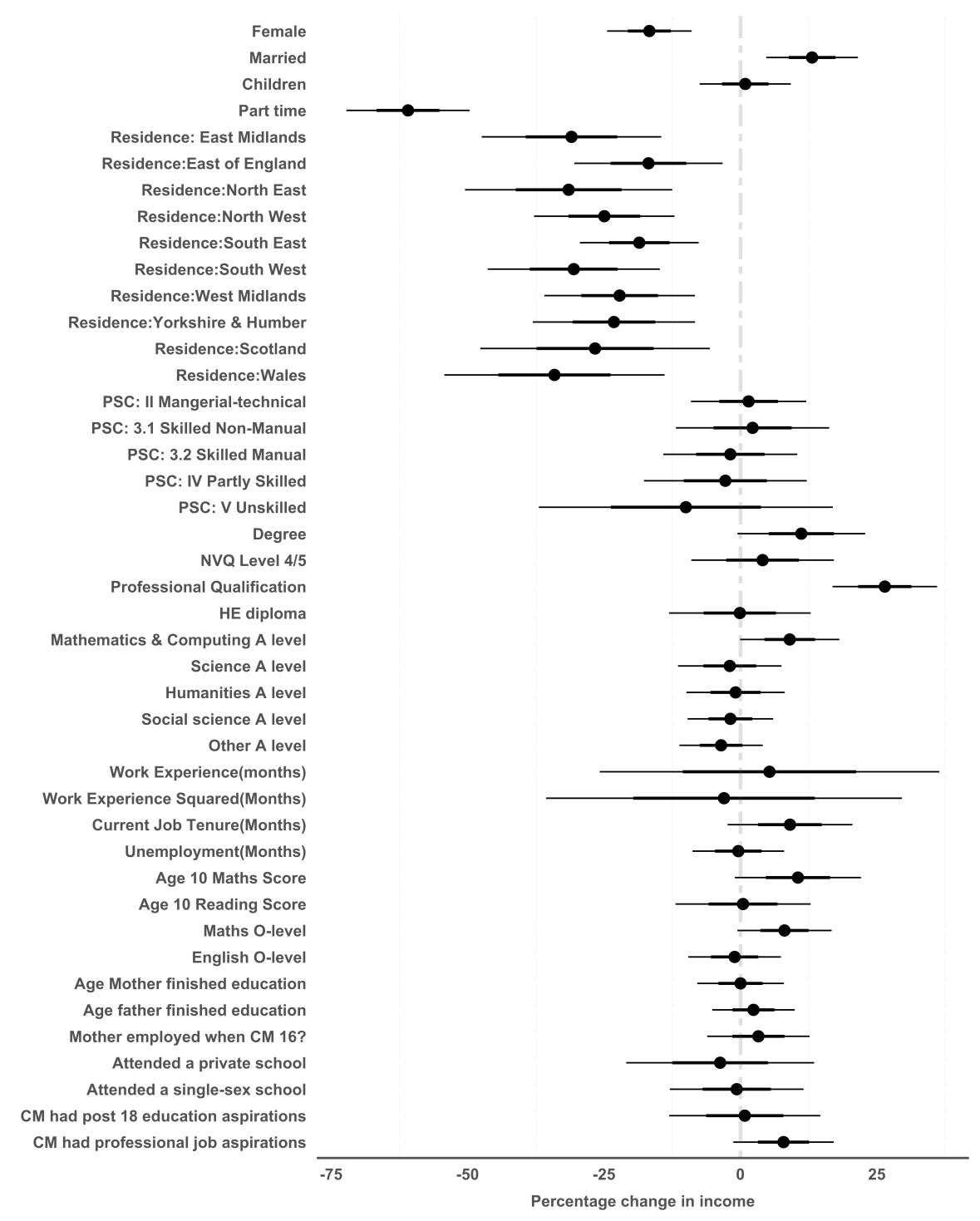

Figure 2: Coefficient plot of estimates for Model 6. Baseline income is approximately $£ 43,670$ [£34,690:£54,960], and is based on an individual who is male, single, has no children, works in a professional occupation, resides in London, has one A level and has 1 standard deviation below average work experience, unemployment, current job tenure, ability scores at age 10 in mathematics and reading, $\mathrm{O}$ level mathematics and English scores, age that their mother and father finished education, and whose mother was employed when they were 16, attended a mixed state school and who did not hold post-18 education and professional occupation aspirations

cannot test whether it is evident on graduation.

\section{Model 6}

While it is less parsimonious, Model 6 raises some doubts about the A-level mathematics and computing coefficient. None of the mathematics predictors (age 10 maths score, O-level attainment and A-level completion) are over two standard deviations away from zero, but all are close. This could suggest that there 
is not a robust premium associated with A-level mathematics for this cohort. Similar to Gelman and Loken (2008) garden of forking paths idea, whether A-level mathematics (and computing) is statistically significant is dependent on analytical decision trajectories. In other words, the effect drops in and out of statistical significance when different combinations of variables are included to address issues of omitted variable bias as well as when including various interaction effects.

We might interpret this by being more cautious regarding claims of a universal wage premium for A-level mathematics and computing, particularly when analysis of interactions suggests that this effect is confined to smaller sub-groups. That said, the direction and strength of these three different kinds of mathematics predictors is striking. It might well be that the marginality of the statistical significance is a function of the sample size and so it would be unwise to dismiss evidence of the premium too hastily. Although Dolton and Vignoles controlled for mathematical ability at age 16 they did not include O-level mathematics in the final reported model. A national qualification is a clear signal of ability and so raises the potential for different theoretical interpretations. Model 6 shows that the A-level mathematics coefficient, though at the margins of statistical significance, appears strong even when including O-level outcomes.

\section{Prediction}
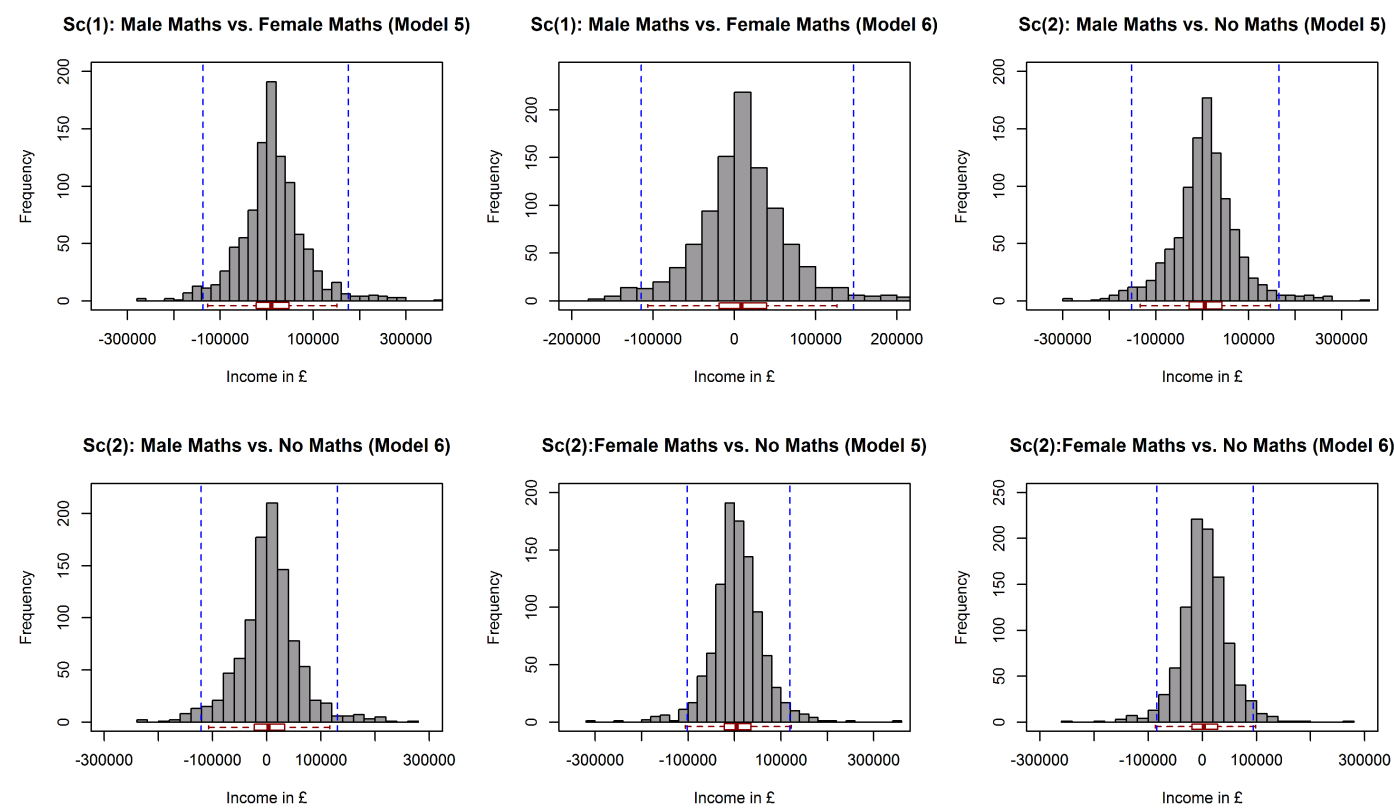

Figure 3: Histograms of predicted earnings for scenario 1 and 2

Analysing predicted earnings allows us to explore age-34 salaries for particular cases. We have chosen two specific interests: gender differences and mathematics participation differences. For this purpose we utilise the strong simulation capabilities within $\mathrm{R}$ to randomly generate predictive distributions based on the summation of regression coefficients in both Model 5 and Model 6 (see Gelman and Hill 2007, pp. 137-153). Our first scenario considers gender differences based on an individual that is married, has at least one child, works a full-time professional job in London, has a degree and a mathematics and/or computing A-level. This individual has below average scores for work experience, unemployment time, current tenure and age 10 ability scores. The second scenario looks at specific differences in earnings when an individual has or does not have an A-level in mathematics. This proposed individual is married, has at least one child, works in a full-time professional job in London, has a degree, a science A-level, humanities A-level and a social 
science A-level, has average work experience, unemployment time, current tenure and ability scores. For the Model 6 predictions, all additional continuous inputs are held at one standard deviation below the mean and the discrete variables are held at zero. Salary predictions based on 1000 random draws from the predictive distribution of earnings are displayed in Figure 3. The earnings comparisons are displayed for Model 5 and Model 6. Each histogram displays the predicted difference that is calculated by subtracting the exponentiated values for the comparison group from the original group. Each histogram represents the spread of values and demonstrates the uncertainty inherent in predicting earnings. The vertical dashed lines indicate the upper and lower bounds of the confidence interval and the small horizontal boxplots indicate the median and upper and lower quartiles of the distribution.

The plots show that the individuals in these scenarios are high earners, which is due to their high-level academic ability, location in London and professional jobs. However, the differences between the simulated individuals are striking in both scenarios. For scenario 1, the predicted annual difference in earnings between men and women is substantial with a mean of approximately $£ 15,200$ for Model 5 and $£ 11,000$ for Model 6. In scenario 2 using Model 5, the predicted difference between those with and without mathematics was approximately $£ 5500$ for males and $£ 6400$ for females. Using Model 6 , the predicted difference between those with and without mathematics was approximately $£ 4550$ for males and $£ 4160$ for females. While these predictive estimates are subject to both simulation error and substantial uncertainty, these results and the findings from the regression make understanding the nature of any return to A-level mathematics (and/or computing) more challenging. Even if we accept that there is, on average, an earnings premium for A-level mathematics, the situation for individuals is far more nuanced. We have only presented two hypothetical situations here but they indicate an important point, that even though there is probably an average premium of over $10 \%$ at age 34, the predicted difference in earnings between men and women outweighs the difference between individuals with and without A-level mathematics. While this might not be surprising given what we know about earnings, it is important to note this when such results tend to get reduced to their simplest form (e.g. people with A-level maths earn $10 \%$ more).

\section{Conclusions}

In this paper we have repeated Dolton and Vignoles' important research on the wage returns to A-levels by using the more recent 1970 British Cohort Study. The BCS presents different challenges from the NCDS, but it has been possible to update this research by using new approaches to multiple imputation to address missing data concerns. While some questions remain about the robustness of evidence of the return to A-level in our Model 6, there is clear and compelling evidence from the 1970 BCS of a return not only to mathematics ability at the end of primary school but also to maths attainment at O-level and participation in A-level. The marginal significance levels could well be a function of the sample size and given the extent of the imputation required it would be hasty to reject what appears to be a strong positive association between mathematics throughout formal education and later earnings.

The key findings from the analysis of a sample 2027 people from the 1970 BCS are summarised below:

- Among the subset of the 1970 BCS participants who completed at least one A-level, mathematical skills, measured either as ability scores at age 10, in qualification grades at age 16 (O-level) or in completion of A-level mathematics and/or computing, appear to have strong and positive association with future earnings at age 34. Though the results are on the margins of statistical significance they are all large and positive.

- The age-34 wage returns to A-level mathematics between the 1958 NCDS and 1970 BCS seem to have been broadly maintained. For the BCS participants now aged 45, completion of A-level mathematics 
(in 1988) probably predicted their earnings aged 34 (in 2004). No other A-level subject category is associated with a wage premium.

- While the repeat model (Model 5) shows a return of up to $11 \%$, adding various combinations of additional variables (Model 6) results in the A-level mathematics and computing effect dropping in and out of normal statistical significance thresholds. Given the sample size and level of imputation required, this finding should not be hastily dismissed.

- If evidence of a wage premium for A-level mathematics is accepted, then the wide-ranging estimates of earnings for those with this qualification must also be acknowledged. The confidence intervals suggest that the premium on A-level mathematics lies between $2 \%$ and $21 \%$, all other things being equal. For individuals, the premium is influenced upon the combinations of other predictors.

- Females in the 1970 BCS earned around 20\% less than their male contemporaries at age 34 . This means that the earnings difference between males and females is greater than between those with and without A-level mathematics. The return for females with A-level mathematics is greater than that for males based on predictions derived from model 5, but this result is subject to substantial predictive uncertainty as demonstrated by the reversal of the pattern with predictions derived from model 6 .

- Regional variations in earnings are, as expected, substantial with much lower average pay outside London.

Our updating of Dolton and Vignoles' research is congruent with the growing body of work that highlights the economic return to mathematics skills in the jobs market. While the effect sizes of the mathematics related predictors suggests that those respondents in the 1970 BCS with higher general mathematical competence do seem to earn more, the extent to which A-level mathematics signals general aptitudes and attitudes, as well as specific mathematical skills, is unclear.

Adopting a human capital argument, one explanation of our analysis would be that A-level mathematical study inculcated some specific mathematics skills that were rewarded in the workplace for this 1970 cohort. The fact that our final model indicates that mathematics skills at age 10,16 and 18, or proxies thereof, all contributed to earnings raises questions about whether it is A-level mathematics per se that is important, or studying mathematics at that level. Caution is needed when interpreting these analyses in contemporary policy settings because the data relates to schooling that took place in the 1980s and the earnings of 34-yearolds in 2004. Despite this caveat, the level of mathematical study remains an important question in light of the current policy that aims for up to 250,000 young people per year to take up new Core Maths qualifications after GCSE.

Alternatively, drawing on qualifications signalling theory, and knowing the strong correlation between attainment at age 16 and A-level mathematics participation and performance (Noyes 2009), one might conclude that O-level mathematics performance is sufficient to signal relative mathematical competence for educational selection (e.g. for degrees) or for filtering into employment pathways. If A-level mathematics has additional signalling potential in educational and employment selection, it might be that a large expansion in Core Maths uptake has little impact on future earning for this group because A-level mathematics remains the stronger signal for the required abilities, attitudes and attributes.

Whether human capital or signal explanations are adopted, the question remains as to what latent construct is being rewarded: specific mathematical abilities or more general attitudes and aptitudes. There is a paucity of research exploring what types of (mathematical) thinking or skills, if any, are acquired in studying A-level mathematics (see Attridge and Inglis 2013, for one analysis of contemporary A-level mathematics learning). Further research is needed on this question and our ongoing work exploring the returns to mathematics across working lives in the NCDS and BCS aim to shed some light on this important issue. 


\section{Acknowlegements}

This research is part of the Rethinking the Value of Advanced Mathematics Participation project, funded by the Nuffield Foundation (EDU/41221). We are grateful to the project advisory group members John MacInnes, Anna Vignoles, Jeremy Hodgen, Emma Smith and Vinay Kathotia for their critical feedback on earlier work. We are also grateful for the support of the University of Nottingham High Performance Computing facility. Lastly, we are indebted to the Centre for Longitudinal Studies, Institute of Education for the use of these data and to the UK Data Archive and Economic and Social Data Service for making them available. However, all responsibility for the analysis and interpretation remains solely with the authors.

\section{References}

Abayomi, K., Gelman, A., and Levy, M. (2008). "Diagnostics for multivariate imputations". Journal of the Royal Statistical Society Series C 57.3, pp. 273-291.

Altonji, J. G., Blom, E., and Meghir, C. (2012). "Heterogeneity in human capital investments: High school curriculum, college major, and careers". NBER Working Paper No. 17985. NBER: Cambridge, MA.

Attridge, N. and Inglis, M. (2013). "Advanced mathematical study and the development of conditional reasoning skills". PLOS ONE 8.7. DoI: 10.1371/journal . pone. 0069399.

Butler, N., Bynner, J. M., and London Institute of Education, Centre for Longitudinal Studies University of (2013). 1970 British cohort study: Sixteen-year follow-up, 1986 [computer file] (5th edn) [Colchester, Essex, UK Data Archive (distributor)], SN: 3535.

Butler, N., Bynner, J. M., and London Institute of Education, Centre for Longitudinal Studies University of (2014). 1970 British cohort study: Ten-year follow-up, 1980 [computer file]. (5th edn) [Colchester, Essex, UK Data Archive (distributor)], SN: 3723.

Bynner, J. and Parsons, S. (1997). Does numeracy matter? Evidence from the National Child Development Study on the Impact of Poor Numeracy on Adult Life. London, Basic Skills Agency.

Bynner, J. M. and London Institute of Education, Centre for Longitudinal Studies University of (2013). 1970 British cohort study: Twenty-six-year follow-up, 1996 [computer file]. (4th edn) [Colchester, Essex, UK Data Archive (distributor)], SN: 3833.

Crawford, C. and Cribb, J. (2013). Reading and maths skills at age 10 and earnings in later life: a brief analysis using the British cohort study. London: Centre for Analysis of Youth Transitions, Institute of Education, University of London.

Dearing, R. (1996). Review of qualifications for 16-19 year olds. Hayes, Middlesex: SCAA Publications.

Department of Employment, Employment Market Research Unit (2013). National survey of 1980 graduates and diplomats, 1986-1987 [computer file] [Colchester, Essex, UK Data Archive (distributor)], SN: 2314.

Dolton, P. and Vignoles, A. (1999). The economic case for reforming A-levels. CEP Discussion Papers dp0422, London: Centre for Economic Performance, LSE.

Dolton, P. and Vignoles, A. (2002). "The return of post-compulsory school mathematics study". Economica 69 (273), pp. 113-141.

Dong, Y. and Peng, C-Y.J (2013). "Principled missing data methods for researchers". SpringerPlus 2 (222).

Gelman, A. and Hill, J. (2007). Data analysis using regression and multilevel/hierarchical models. Cambridge: Cambridge University Press.

Gelman, A. and Loken, E. (2008). "The garden of forking paths: Why multiple comparisons can be a problem when there is no 'fishing expedition' or 'p-hacking' and the research hypothesis was posited ahead of time". Unpublished, Columbia University, New York. URL: http : / www . stat . columbia . edu/ gelman/research/unpublished/p_hacking.pdf. 
Gelman, A., Carlin, J.B., Stern, H.S., Dunson, D.B., Vehtari, A., and Rubin, D.B. (2014). Bayesian data analysis. 3rd Edition. Boca Raton, FL: CRC Press.

Gibb, N. (2015). Nick Gibb's speech on government's maths reforms. URL: https : / / www . gov . uk / government/speeches/nick-gibb-speech-on-governments-maths-reforms.

Gove, M. (2015). Michael Gove speaks to the Royal Society on maths and science. URL: https: //www . gov .uk/government/speeches/michael-gove-speaks-to-the-royal-society-on-mathsand-science.

Graham, J.W., Olchowski, A.E., and Gilreath, T.D. (2008). "How many imputations are really needed? Some practical clarifications of multiple imputation theory". Prevention Science 8 (3), pp. 206-213.

Greenwood, C., Harrison, M., and Vignoles, A. (2011). The labour market value of STEM qualifications and occupations: An analysis for the Royal Academy of Engineering. London: Institute of Education.

Hanushek, E. A., Schwerdt, G., Wiederhold, S., and Woessmann, L. (2015). "Returns to skills around the world: Evidence from PIAAC". European Economic Review 73 (C), pp. 103-130.

Hardt, J., Herke, M., and Leonhart, R. (2012a). "Auxiliary variables in multiple imputation in regression with missing x: A warning against including too many in small sample research". BMC Medical Research Methodology 12, pp. 184-197.

Hardt, J., Herke, M., and Leonhart, R. (2012b). "Investment in human capital and personal income distribution”. Journal of Political Economy 66 (4), pp. 281-302.

Hawkes, T. and Savage, M. (1999). Measuring the mathematics problem. London: The Engineering Council.

Hodgen, J., Pepper, D., Sturman, L., and Ruddock, G. (2010). Is the UK an outlier? An international comparison of upper secondary mathematics education. London: The Engineering Council.

Little, R. and Rubin, D.B. (1987). Statistical analysis with missing data. New York: Wiley.

Little, R. and Rubin, D.B. (2002). Statistical analysis with missing data. 2nd Edition. New York: Wiley.

Mincer, J. (1974). Schooling, experience, and earnings. New York: Wiley.

Morgan, N. (2014). Nicky Morgan speaks at launch of Your Life campaign. uRL: https://www . gov . uk/ government/speeches/nicky-morgan-speaks-at-launch-of-your-life-campaign.

Noyes, A. (2009). "Exploring social patterns of participation in university-entrance level mathematics in England". Research in Mathematics Education 11 (2), pp. 167-183.

Royston, P. and White, I.R. (2011). "Multiple imputation by chained equations (MICE): Implementation in Stata". Journal of Statistical Software 45 (4), pp. 1-20.

Rubin, D.B. (1976a). "Inference and missing data". Biometrika 63, pp. 1-20.

Rubin, D.B. (1976b). "Multiple imputation after 18+ years". Journal of the American Statistical Association 91 (434), pp. 473-489.

Schoon, I., Ross, A., and Martin, P. (1976). "Science related careers: Aspirations and outcomes in two British cohort studies". Equal Opportunities International 26 (2), pp. 129-143.

Schultz, T.W. (1961). "Investment in human capital". The American Economic Review 51 (1), pp. 1-17.

Spence, M. (1973). "Job market signaling”. The Quarterly Journal of Economics 87 (3), pp. 355-374.

Tabachnick, B.G. and Fidell, L.S. (2012). Using multivariate statistics. Needham Heights, MA: Allyn \& Bacon.

Truss, E. (2013). Institute of Education open lecture on A-level reforms. uRL: https : / /www . gov . uk / government/speeches/institute-of-education-open-lecture-on-a-level-reforms.

University of London, Institute of Education, Centre for Longitudinal Studies (2008a). 1970 British Cohort Study: Employment histories, 1996-2004 [computer file]. (2nd edn) [Colchester, Essex, UK Data Archive (distributor)], August 2008. SN: 5613.

University of London, Institute of Education, Centre for Longitudinal Studies (2008b). National Child Development Study: Sweep 5, 1991 [computer file]. (2nd edn) City University, Social Statistics Research Unit, [Original data producer(s)[Colchester, Essex, UK Data Archive (distributor)], August 2008. SN: 5567. 
University of London, Institute of Education, Centre for Longitudinal Studies (2013a). 1970 British Cohort Study: Thirty-eight-year follow-up, 2008-2009 [computer file]. (3rd edn) [Colchester, Essex, UK Data Archive (distributor)], SN: 6557.

University of London, Institute of Education, Centre for Longitudinal Studies (2013b). 1970 British Cohort Study: Thirty-four-year follow-up, 2004-2005 [computer file]. (3rd edn) [Colchester, Essex, UK Data Archive (distributor)]. SN: 5585.

University of London, Institute of Education, Centre for Longitudinal Studies (2013c). 1970 British cohort study: Twenty-nine-year follow-up, 1999-2000 [computer file]. (3rd edn) Joint Centre for Longitudinal Research, [original data producer(s)] [Colchester, Essex, UK Data Archive (distributor)],May 2013. SN: 5558 .

University of London, Institute of Education, Centre for Longitudinal Studies (2014). 1970 British Cohort Study: Forty-two-yearfollow-up, 2012 [computer file] [Colchester, Essex, UK Data Archive (distributor)], SN: 7473.

Van Buuren, S., Boshuizen, H., and Knook, D. (1999a). "MICE: Multivariate imputation by chained equations in R". Journal of Statistical Software 45 (3), pp. 1-67.

Van Buuren, S., Boshuizen, H., and Knook, D. (1999b). "Multiple imputation of missing blood pressure covariates in survival analysis". Statistics 18 (6), pp. 681-694.

Von Hippel, P.T. (2007). "Regression with missing Ys: An improved strategy for analyzing multiply imputed data". Sociological Methodology 37 (1), pp. 83-117.

Von Hippel, P.T. (2009). "How to impute interactions, squares, and other transformed variables". Sociological Methodology 39 (1), pp. 265-291.

Weiss, A. (1995). "Human capital vs. signalling explanations of wages". The Journal of Economic Perspectives 9 (4), pp. 133-154.

White, I.R., Royston, P., and Wood, A. (2011). "Multiple imputation using chained equations: Issues and guidance for practice". Statistics in Medicine 30 (4), pp. 377-399. 